\title{
Clinical DRUJ instability does not influence the long-term functional outcome of conservatively treated distal radius fractures
}

\author{
M. M. E. Wijffels ${ }^{1}$ P. Krijnen $^{1}$ - I. B. Schipper ${ }^{1}$
}

Received: 16 September 2015 / Accepted: 25 December 2015 / Published online: 29 January 2016

(C) The Author(s) 2016. This article is published with open access at Springerlink.com

\begin{abstract}
Objective The presence of distal radioulnar joint (DRUJ) instability remains often unnoticed initially, but may worsen functional outcome of distal radius fractures (DRF). The aim of this study was to evaluate the influence of concurring clinical DRUJ instability on the outcome of conservatively treated DRF.

Methods In a retrospective cohort study, all unilateral, conservatively treated DRF patients were invited for physical examination, CT scan of both wrists and filling out questionnaires. Static and dynamic DRUJ instability were clinically tested.

Results Forty-nine DRF patients with a mean follow-up of 4.2 years (SD 0.5) were assessed. Seventeen patients tested positive for DRUJ instability. No differences were found in baseline characteristics between the DRUJ stable and unstable group. Apart from wrist flexion, no statistical significant differences in outcome was found between patients with and without DRUJ instability.

Conclusion The presence of clinical DRUJ instability does not seem to affect functional outcome of conservatively treated distal radius fractures at long-term follow-up.
\end{abstract}

keywords Distal radioulnar joint · Instability · Distal radius fracture $\cdot$ Wrist

\footnotetext{
M. M. E. Wijffels

mmewijffels@hotmail.com

1 Department of Surgery-Traumatology, Leiden University Medical Center, P.O. Box 9600, 2300 RC Leiden, The Netherlands
}

\section{Introduction}

Distal radius fractures (DRF) comprise one in six fractures that present to the emergency department [1-3]. The treatment decision between surgical or conservative fracture management is based on several factors including the type and complexity of the fracture, bone quality, the surgeon's experience and patient characteristics [4]. The majority (50$80 \%$ ) of DRF is still treated conservatively, although there is an increasing tendency towards surgical treatment $[5,6]$.

One of the complicating factors with a potentially negative influence on the outcome of DRF treatment is concurring distal radial ulnar joint (DRUJ) instability. The incidence of DRUJ instability after DRF varies from 0 to $35 \%$ at 1 year after a distal radius fracture [7-10] . Lindau found that DRUJ instability was independently associated with worse outcome after DRF, showing significantly more pain and lower wrist scores for DRUJ unstable patients [7, 8]. These findings resulted from DRF patients after a variety of treatment modalities, amongst which surgery. In this study, the surgery itself may have influenced the outcome [7, 8]. Currently, it is unknown how the outcome of non-operatively treated DRF is influenced by coexisting DRUJ instability. The aim of this study therefore was to assess the influence of clinical DRUJ instability on the longterm outcome of conservatively treated DRFs.

\section{Patients and methods}

All adults treated conservatively for a DRF between May 2008 and February 2010 in the Leiden University Medical Center were eligible for inclusion in this study. Patients were excluded if they were (1) unwilling or unable to provide informed consent or had (2) systemic diseases such as rheumatoid arthritis and SLE, or had (3) contralateral 
wrist injury. All eligible patients received an invitational letter for a study visit according to the protocol, as approved by the institutional medical ethics review board.

\section{Visit}

During the research visit DRUJ instability of both the injured and non-injured wrist was tested by an experienced trauma surgeon not involved in the initial treatment and unaware of the injured side. Static instability was tested using the stress test $[8,11,12]$. The test was considered positive if there was more anterioposterior movement, in any direction, of the ulna relative to the stabilized radius in the injured wrist compared to the uninjured wrist. Dynamic instability was tested using the clunk test [13]. The test was considered positive if a "clunk" was palpable for either the patient or examiner, during pronosupination of the lower arm with the wrist held between the examinator's thumb and index finger.

Further physical examination of both wrists consisted of measurement of range of motion and grip- and pinch strength for both the injured and non-injured wrist. Range of motion was measured using a goniometer. Grip and pinch strength were based on the mean value of three successive measurements using a $\mathrm{Jamar}^{\circledR}$ Hydraulic Hand Dynamometer and a Jamar ${ }^{\circledR}$ Hydraulic Pinch Gauge, respectively. Maximum range of motion of the injured wrist was expressed in degrees and as a percentage of the non-injured wrist.

\section{Radiological evaluation}

Conventional trauma radiographs in lateral and anterioposterior view were evaluated by one observer (MW) to determine the fracture classification according to the Comprehensive Classification of Fractures [14]. CT scans of both wrists were obtained and evaluated for radiocarpal arthritic changes according to the classification of Knirk and Jupiter and for union of the ulnar styloid, if a fracture was previously present [15]. The CT scans were made at 3-mm intervals using an Aquilion One (Toshiba Medical Systems). Axial sections of the wrist were obtained with the arm outstretched position above the head in prone position to minimize the exposure to radiation.

\section{Patient reported outcome}

Participants scored pain on a visual analog scale five times for the posttraumatic wrist, indicating perceived pain (1) in rest, (2) with $10 \mathrm{~kg}$ loadbearing with the elbow extended and (3) with $10 \mathrm{~kg}$ loadbearing with the elbow $90^{\circ}$ flexed, (4) during pronosupination without loadbearing and (5) during pronosupination with $10 \mathrm{~kg}$ of loadbearing. Furthermore, the Disabilities of the Arm, Shoulder and Hand
(DASH) score, Modified Mayo Wrist Score (MMWS) and Gartland and Werley score were filled out by the participants [16-18].

\section{Statistical analysis}

Baseline characteristics and outcome scores of the clinically DRUJ stable and unstable groups were compared. The static DRUJ unstable group was compared to the stable group, as was the dynamic DRUJ unstable group. Continuous data were compared between groups by the independent samples $t$ test, categorical data by the Pearson's Chisquare test. Analyses were performed using SPSS version 20 (SPSS Inc, Chicago IL). $p$ values below 0.05 were considered statistically significant.

\section{Results}

In total, 156 patients met the inclusion criteria and were sent an invitational letter for a study visit. Thirty-four patients were lost to follow-up and 73 were unwilling to participate. The resulting 49 participants provided written informed consent before examination. No differences were found in age, gender or fracture classification comparing participants with no participants (data not shown).

The study group consisted of 10 men and 39 women, both distributed without a significant difference over the DRUJ stable and unstable group Mean age was 60.8 years (SD 16.2). Mean follow-up after trauma was 4.2 years (SD 0.5). Seventeen of the 49 patients tested positive for DRUJ instability. The groups with and without DRUJ instability were similar with respect to age, gender, dominant hand injured, fracture characteristics and degree of radiocarpal arthritis. No arthritic changes of the DRUJ were found. In the DRU stable patients 13 patients had an accompanying ulnar styloid process (PSU) of which 7 united. In the DRU unstable patients 11 patients had an accompanying ulnar styloid process (PSU) of which 4 united. No significant differences were found in PSU-union between groups (Table 1).

\section{Range of motion and strength}

In patients with an unstable DRUJ flexion and extension averaged $81^{\circ}\left(\right.$ range $58^{\circ}-102^{\circ}$ ) and $89^{\circ}$ (range $58^{\circ}-110^{\circ}$ ), respectively. Radial deviation averaged $25^{\circ}$ (range $5^{\circ}-40^{\circ}$ ) and ulnar deviation averaged $40^{\circ}$ (range $25^{\circ}-58^{\circ}$ ). The average pronation and supination measured $84^{\circ}$ (range $60^{\circ}-100^{\circ}$ ) and $89^{\circ}\left(\right.$ range $75^{\circ}-110^{\circ}$ ), respectively. In patients with a stable DRUJ of the injured wrist flexion averaged $68^{\circ}$ (range $35^{\circ}-92^{\circ}$ ) and extension $85^{\circ}$ (range $55^{\circ}-105^{\circ}$ ). Radial deviation averaged $24^{\circ}$ (range $6^{\circ}-40^{\circ}$ ) 
Table 1 Baseline characteristics of patients with static distal radioulnar joint instability compared to patients with a stable distal radioulnar joint

\begin{tabular}{|c|c|c|c|}
\hline & DRUJ stable $(n=32)$ & DRUJ instability $(n=17)$ & $p$ value \\
\hline Age (years) [SD] & $61.5[14.6]$ & $59.5[19.3]$ & .686 \\
\hline Follow-up (years) [SD] & $4.2[0.5]$ & $4.1[0.5]$ & .767 \\
\hline Gender & & & .07 \\
\hline Male & 9 & 1 & \\
\hline Female & 23 & 16 & \\
\hline AO classification $(n)$ & & & .448 \\
\hline A & 13 & 10 & \\
\hline B & 4 & 1 & \\
\hline $\mathrm{C}$ & 15 & 6 & \\
\hline Dominant hand injured $(n)$ & & & .426 \\
\hline Yes & 15 & 10 & \\
\hline No & 17 & 7 & \\
\hline PSU-union $(n)$ & & & .185 \\
\hline Yes & 7 & 4 & \\
\hline No & 6 & 7 & \\
\hline No PSU fracture & 19 & 6 & \\
\hline Radio carpal arthritis $(n)$ & & & .138 \\
\hline 0 & 1 & 3 & \\
\hline 1 & 14 & 7 & \\
\hline 2 & 13 & 3 & \\
\hline 3 & 4 & 4 & \\
\hline
\end{tabular}

0 , none; 1 , slight joint-space narrowing; 2 , marked joint-space narrowing, osteophyte formation; 3 , boneon-bone, osteophyte formation, cyst formation and ulnar deviation averaged $40^{\circ}$ (range $21^{\circ}-65^{\circ}$ ). The average pronation and supination measured $87^{\circ}$ (range $68^{\circ}-109^{\circ}$ ) and $92^{\circ}$ (range $60^{\circ}-118^{\circ}$ ), respectively. Function expressed as percentage of the uninjured arm is shown in Table 2. Flexion was found to be statistical significantly better in the DRUJ unstable group. Further results did not differ between patients with and without DRUJ instability.

In patients with an unstable DRUJ the grip and pinch strength averaged $98 \%$ (range 59-115\%) and $101 \%$ (range 51-133\%), respectively, indexing the uninjured for the injured wrist. In patients with a stable DRUJ, the grip and pinch strength averaged $93 \%$ (range 63-132\%) and $95 \%$ (range 50-161\%), respectively, indexing the uninjured for the injured wrist. No differences in strength were found between the groups (Table 2).

\section{Patient reported outcome}

Ten of the DRUJ unstable patients revealed only static DRUJ instability, of which two suffered from wrist pain in rest and seven patients showed both static and dynamic instability, of which one suffered from wrist pain in rest. Two patients suffered from pain prior to the trauma, in the injured wrist.

In the DRUJ unstable group, three patients indicated pain in the injured wrist in rest with a mean of 5.3 (range
0-50). The mean outcome for pain, with $10 \mathrm{~kg}$ loadbearing with the elbow extended, with $10 \mathrm{~kg}$ loadbearing with the elbow $90^{\circ}$ flexed, during pronosupination without loadbearing and during pronosupination with $10 \mathrm{~kg}$ of loadbearing on the VAS was 11.8 (range 0-70), 10.6 (range 0-60), 0.0 (range 0-0) and 11.2 (range 0-70), respectively. Mean DASH score was 10 (range 0-28). One patient did not fulfill the DASH. The MMWS was excellent or good in 16 and poor in one patient. The Gartland and Werley ratings were excellent in 5 patients, good outcome in 9 patients and fair in 3 patients.

In the DRUJ stable group, three patients indicated pain in the injured wrist in rest with a mean of 4.7 (range 0-80). Average outcome for pain with $10 \mathrm{~kg}$ loadbearing with the elbow extended, with $10 \mathrm{~kg}$ loadbearing with the elbow $90^{\circ}$ flexed, during pronosupination without loadbearing and during pronosupination with $10 \mathrm{~kg}$ of loadbearing on the VAS was 9.3 (range 0-60), 7.7 (range 0-90), 3.0 (range 0-60) and 8.9 (range 0-80), respectively. Mean DASH score was 7.9 (range 0-68). The MMWS ratings were excellent or good in 25 patients, satisfactory in 5 and poor in 2 patients. The Gartland and Werley ratings were excellent and good outcome in 25 patients and satisfactory or poor in 7 patients.

There were no significant differences between DRUJ stable and instable groups in terms patient reported outcomes 
Table 2 Functional outcome parameters of patients with stable or unstable distal radioulnar joint

\begin{tabular}{|c|c|c|c|}
\hline & DRUJ stable $(n=32)$ & DRUJ unstable $(n=17)$ & $p$ value \\
\hline Flexion in degrees, mean (range) & $68(35-92)$ & $81(58-102)$ & \\
\hline$\%$ of non-injured wrist & $0.93(0.13)$ & $1.01(0.15)$ & .04 \\
\hline Extension in degrees, mean (range) & $85(55-105)$ & $89(58-110)$ & \\
\hline$\%$ of non-injured wrist & $1.0(0.11)$ & $1.00(0.10)$ & .88 \\
\hline Pronation in degrees, mean (range) & $87(68-109)$ & $84(60-100)$ & \\
\hline$\%$ of non-injured wrist & $0.98(0.09)$ & $0.98(0.09)$ & .95 \\
\hline Supination in degrees, mean (range) & $92(60-118)$ & $89(75-110)$ & \\
\hline$\%$ of non-injured wrist & $1.02(0.15)$ & $0.98(0.14)$ & .28 \\
\hline Radial deviation in degrees, mean (range) & $24(6-40)$ & $25(5-40)$ & \\
\hline$\%$ of non-injured wrist & $1.1(0.36)$ & $1.10(0.40)$ & .89 \\
\hline Ulnar deviation in degrees, mean (range) & $40(21-65)$ & $40(25-58)$ & \\
\hline$\%$ of non-injured wrist & $1.0(0.61)$ & $0.97(0.20)$ & 68 \\
\hline Grip strength, $\%$ of non-injured wrist & $0.93(0.13)$ & $0.98(0.12)$ & .25 \\
\hline Pinch strength, $\%$ of non-injured wrist & $0.95(0.22)$ & $1.01(0.22)$ & .34 \\
\hline DASH & $7.9(16.3)$ & $10.05(9.72)$ & .63 \\
\hline MMWS & $87.03(12.9)$ & $87.06(10.47)$ & .99 \\
\hline Gartland and Werly & $4.2(3.66)$ & $4.9(3.47)$ & .49 \\
\hline Pain injured wrist in rest & $4.7(16.7)$ & $5.3(15.05)$ & .90 \\
\hline Pain injured wrist, carrying $10 \mathrm{~kg}$, with elbow extended & $9.3(18.7)$ & $11.8(23.78)$ & 69 \\
\hline Pain injured wrist, carrying $10 \mathrm{~kg}$, with elbow flexed & $7.7(19.6)$ & $10.6(20.5)$ & 63 \\
\hline Pain injured wrist during pronosupination without load & $3(11.4)$ & $0(0)$ & .29 \\
\hline Pain injured wrist during pronosupination with $10 \mathrm{~kg}$ loadbearing & $8.9(21.1)$ & $11.2(22.05)$ & .72 \\
\hline
\end{tabular}

Results are expressed as mean (SD) unless indicated otherwise

(Table 2). Comparing patients with static or dynamic DRUJ instability separately to stable DRUJ patients, no statistical significant differences were found (data not shown).

\section{Discussion}

Concurring DRUJ instability is assumed to be an independent factor for poor functional outcome in conservatively and operatively treated DRF [8]. This study analyzed the relation between DRUJ instability and functional outcome in a group of conservatively treated DRF patients and found that patients with clinical DRUJ instability, after consolidation of the DRF, had a long-term functional outcome similar to that of patients after DRF without DRUJ instability with a significantly better wrist flexion. To our knowledge, no previous studies focussed on conservatively treated patients solely.

\section{Function}

In the present study, only a significant better flexion of the wrist was found in the DRUJ unstable patients. No further differences in function or strength were found, comparing patients with a stable DRUJ to patients with an unstable
DRUJ. Since flexion and extension of the wrist primarily concern the radiocarpal joint and not so much the DRUJ, finding a difference was not anticipated for this motion. The greater range of flexion in the DRUJ unstable group may be spurious given the relatively small number of patients and the absence of other plausible explanations. However, the expected difference in pronosupination, a movement mainly involving the DRUJ, was not found. A reason for this may be the influence of muscle dependent stabilizers of the DRUJ, such as the extensor carpi ulnaris tendon, the pronator quadratus muscle and the radioulnar interosseous membrane [19-21]. During pronosupination the muscles tighten resulting in a more stable DRUJ, independent of ligamentous stabilization. These muscle-tension dependent stabilizers may also be the reason for absence of difference in grip- and pinch strength; a finding corresponding with the results of Lindau et al. [22]. Since muscle relaxation is warranted during the clinical tests, the DRUJ is no longer supported resulting in a positive testing result.

\section{Ulnar styloid}

Distal radial ulnar joint instability results from malfunctioning of joint stabilizing structures. These stabilizers are, among others, ligamentous and therefore invisible on 
conventional radiographs and computed tomography (CT) without contrast. Secondary signs may be visualized using these radiological techniques. Since the triangular fibrocartilage complex (TFCC) attaches to the ulnar styloid process (USP), non-union of the USP may indicate loss of TFCC as a stabilizing factor. Static and dynamic DRUJ instability was found in 33 and $17 \%$, respectively, of the patients in the current study. No difference was found in the number of ulnar styloid non-unions in DRUJ unstable patients compared to DRUJ stable patients. This implies that the TFCC is not the only stabilizing structure and that non-union of the ulnar styloid has no influence on DRUJ stability, which corresponds with literature $[9,10,23-26]$.

\section{Pain}

According to Stoffelen et al., DRUJ instability may cause ongoing wrist pain [27]. Lindau et al. found no statistical difference in pain comparing lax DRUJ patients with DRUJ stable patients [22]. Similarly, in this study we found no statistically significant difference in pain between patients with or without clinical DRUJ instability. The absent difference in pain scores may be due to the long follow-up of this (4 years) and Lindau's study (6 years), compared to the follow-up of 1 year in the study of Stoffelen et al. Still these conclusions should be interpreted with caution since ongoing pain after distal radius fractures can be caused by several factors which are not all evaluated in this and other studies [22, 28-30].

Arthritic changes of the DRUJ after chronic instability have been described [31]. For this reason, it is remarkable that no arthritic changes in the DRUJ were found, despite symptomatic wrists in some patients. These results may be caused by the fact that symptoms were not attributed to a specific wrist region, e.g., the DRUJ region or follow-up as too short to develop DRUJ arthritic changes. Furthermore most distal radius fractures did not involve the DRUJ and may therefore not result in cartilage damage, a finding that may be seen in a posttraumatic incongruent DRUJ.

\section{Shortcomings}

The shortcomings of this study include the small number of patients analyzed, due to the loss of follow-up of many patients and refusal to participate of many others. However, no differences in age or fracture type was found comparing participant with no participants so the participants may be assumed to be representative for the whole group although we were not informed about residual complaints in nonparticipants. Another study limitation is that, although widely used, the reliability and accuracy of the tests for determination of clinical DRUJ instability is uncertain. [8, 13, 27, 32] This may be due to the subjective qualification of "more laxity compared to the non-injured wrist" when using the stress test. Since the tests were done only once, by one investigator we were not able to establish inter- and intra-observer variation. In the absence of other clinical tests, the stress test and clunk test were used to mimic daily clinical practice and enable comparison of the results with published literature.

Furthermore, no information was available on the presence of DRUJ instability before the distal radius fracture. This aspect is hard to evaluate in any study since this pretrauma information is generally lacking. Mikic [33] showed an increasing percentage of TFCC tears during lifespan, suggesting that degenerative DRUJ instability may have been present in some of the patients.

\section{Conclusion}

Based on this study with some shortcomings, DRUJ instability does not seem to affect clinical outcome of conservatively treated distal radius fractures after long-term followup. Conservative treatment of secondarily diagnosed DRUJ instability after a DRF, seems to be a justified treatment.

\section{Compliance with ethical standards}

Conflict of interest M. M. E. Wijffels, P. Krijnen and I. B. Schipper declare that there is no conflict of interest.

Ethical approval This study was conducted with approval of the local medical ethical committee.

Informed consent All participant of this study were included after written informed consent.

Open Access This article is distributed under the terms of the Creative Commons Attribution 4.0 International License (http://creativecommons.org/licenses/by/4.0/), which permits unrestricted use, distribution, and reproduction in any medium, provided you give appropriate credit to the original author(s) and the source, provide a link to the Creative Commons license, and indicate if changes were made.

\section{References}

1. Hollingsworth R, Morris J. The importance of the ulnar side of the wrist in fractures of the distal end of the radius. Injury. 1976;7(4):263-6.

2. Lindau TR, Aspenberg P, Arner M, Redlundh-Johnell I, Hagberg L. Fractures of the distal forearm in young adults. An epidemiologic description of 341 patients. Acta Orthop Scand. 1999;70:124-8.

3. Sammer DM, Shah HM, Shauver MJ, Chung KC. The effect of ulnar styloid fractures on patient-rated outcomes after volar locking plating of distal radius fractures. J Hand Surg Am. 2009;34:1595-602. 
4. Karagiannopoulos C, Sitler M, Michlovitz S, Tierney R. A descriptive study on wrist and hand sensorimotor impairment and function following distal radius fracture intervention. J Hand Ther. 2013;26(3):204-14.

5. Nellans KW, Kowalski E, Chung KC. The epidemiology of distal radius fractures. Hand Clin. 2012;28:113-25.

6. Taras JS, Ladd AL, Kalainov DM, Ruch DS, Ring DC. New concepts in the treatment of distal radius fractures. Instr Course Lect. 2010;59:313-32.

7. Lindau T, Adlercreutz C, Aspenberg P. Peripheral tears of the triangular fibrocartilage complex cause distal radioulnar joint instability after distal radial fractures. J Hand Surg Am. 2000;25(3):464-8.

8. Lindau T, Hagberg L, Adlercreutz C, Jonsson K, Aspenberg P. Distal radioulnar instability is an independent worsening factor in distal radial fractures. Clin Orthop Relat Res. 2000;376:229-35.

9. Wijffels M, Ring D. The influence of non-union of the ulnar styloid on pain, wrist function and instability after distal radius fracture. J Hand Microsurg. 2011;3:11-4.

10. Krämer S, Meyer H, O'Loughlin P, Vaske B, Krettek C, Gaulke $\mathrm{R}$. The incidence of ulnocarpal complaints after distal radial fracture in relation to the fracture of the ulnar styloid. J Hand Surg Eur. 2013;38:710-7.

11. Morrissy RT, Nalebuff EA. Dislocation of the distal radioulnar joint: anatomy and clues to prompt diagnosis. Clin Orthop Relat Res. 1979;144:154-8.

12. Pirela-Cruz MA, Goll SR, Klug M, Windler D. Stress computed tomography analysis of the distal radioulnar joint: a diagnostic tool for determining translational motion. J Hand Surg Am. 1991;16:75-82.

13. Jupiter JB. Commentary: the effect of ulnar styloid fractures on patient-rated outcomes after volar locking plating of distal radius fractures. J Hand Surg Am. 2009;34:1603-4.

14. Müller ME, Allgöwer M, Schneider R, Willenegger H. Manual of internal fixation. 3rd ed. New York: Springer; 1991.

15. Knirk JL, Jupiter JB. Intra-articular fractures of the distal end of the radius in young adults. J Bone Joint Surg Am. 1986;68(5):647-59.

16. Hudak PL, Amadio PC, Bombardier C. Development of an upper extremity outcome measure: the DASH (Disabilities of the Arm, Shoulder and Hand). Am J Ind Med. 1996;29:602-8.

17. Amadio PC, Berquist TH, Smith DK, Ilstrup DM, Cooney WP 3rd, Linscheid RL. Scaphoid malunion. J Hand Surg Am. 1989;14:679-87.

18. Gartland JJ Jr, Werley CW. Evaluation of healed Colles' fractures. J Bone Joint Surg Am. 1951;33:895-907.
19. Garcia-Elias M. Soft-tissue anatomy and relationships about the distal ulna. Hand Clin. 1998;14:165-76.

20. Johnson RK, Shrewsbury MM. The pronator quadratus in motions and in stabilization of the radius and ulna at the distal radioulnar joint. J Hand Surg Am. 1976;1:205-9.

21. Hotchkiss RN, An KN, Sowa DT, Basta S, Weiland AJ. An anatomic and mechanical study of the interosseous membrane of the forearm. Pathomechanics of proximal migration of the radius. $\mathbf{J}$ Hand Surg Am. 1989;14:256-61.

22. Lindau T, Runnquist K, Aspenberg P. Patients with laxity of the distal radioulnar joint after distal radial fractures have impaired function, but no loss of strength. Acta Orthop Scand. 2002;73:151-6.

23. Buijze G, Ring D. Clinical impact of united versus nonunited fractures of the proximal half of the ulnar styloid following volar plate fixation of the distal radius. J Hand Surg Am. 2010;35:223-7.

24. Kim JK, Koh YD, Do NH. Should an ulnar styloid fracture be fixed following volar plate fixation of a distal radial fracture? $\mathbf{J}$ Bone Joint Surg Am. 2010;92:1-6.

25. Souer JS, Ring D, Matschke S, Audige L, Marent-Huber M, Jupiter JB. Effect of an unrepaired fracture of the ulnar styloid base on outcome after plate-and-screw fixation of a distal radial fracture. J Bone Joint Surg Am. 2009;91:830-8.

26. Zenke Y, Sakai A, Oshige T, Moritani S, Nakamura T. The effect of an associated ulnar styloid fracture on the outcome after fixation of a fracture of the distal radius. J Bone Joint Surg Br. 2009;91:102-7.

27. Stoffelen D, De Smet L, Broos P. The importance of the distal radioulnar joint in distal radial fractures. J Hand Surg Br. 1998;23:507-11.

28. Watanabe A, Souza F, Vezeridis PS, Blazar P, Yoshioka H. Ulnarsided wrist pain. II. Clinical imaging and treatment. Skeletal Radiol. 2010;39:837-57.

29. Hauck RM, Skahen J 3rd, Palmer AK. Classification and treatment of ulnar styloid non-union. J Hand Surg. 1996;21:418-22.

30. Cerezal L, del Piñal F, Abascal F, Garcia-Valtuille R, Pereda T, Canga A. Imaging findings in ulnar-sided wrist impaction syndromes. Radiographics. 2002;22:105-21.

31. Kakar S, Carlsen BT, Moran SL, Berger RA. The management of chronic distal radioulnar instability. Hand Clin. 2010;26:517-28.

32. Szabo RM. Distal radioulnar joint instability. J Bone Joint Surg. 2006;88:884-94.

33. Mikic ZD. Age changes in the triangular fibrocartilage of the wrist joint. J Anat. 1978;126:367-84. 